\title{
Co-producing urban knowledge in Angola and Mozambique: towards meeting SDG 11
}

\author{
Sylvia Croese $\mathbb{i D}^{1 凶}$, Massamba Dominique ${ }^{2}$ and Inês Macamo Raimundo ${ }^{3}$
}

The need to make cities in Africa more inclusive, safe, resilient and sustainable (Sustainable Development Goal 11) is undisputed as rapid urban growth rates are set to make the African region a key hub in the global transition to a predominantly urban world. This perspective presents findings from a research project conducted in the cities of Luanda, Angola and Maputo, Mozambique, which used citizen science to generate data on selected indicators of the urban Sustainable Development Goal and use this data to inform more inclusive, sustainable and participatory urban planning and policymaking. Based on the research, we argue that meeting SDG 11 will ultimately depend on the spaces and mechanisms for knowledge co-production and sharing that are produced in the process.

npj Urban Sustainability (2021)1:8; https://doi.org/10.1038/s42949-020-00006-6

\section{INTRODUCTION}

The need to make cities in Africa 'more inclusive, safe, resilient and sustainable', as encapsulated in the stand-alone urban goal 11 adopted as part of the 17 United Nations (UN) Sustainable Development Goals (SDGs) in 2015, is undisputed as rapid urban growth rates are set to make the African region a key hub in the global transition to a predominantly urban world. This will not only require new and more transformative public policies that address the social, economic and environmental dimensions of sustainable development, but also data to inform planning, implementation and reporting.

However, statistical systems in Africa tend to be weak and SDG indicator data sources are often not available, outdated or not disaggregated to the required level ${ }^{1}$. As a result, approximately six out of every ten SDG indicators cannot be tracked ${ }^{2}$. It does not help that as of July 2020, only about half of the total number of 231 unique indicators that compose the SDG monitoring framework are Tier I indicators, which represent conceptually clear indicators with an internationally established and available methodology and regularly produced data by at least $50 \%$ of countries (see Box 1). Moreover, in spite of the UN's call for a global 'data revolution' ${ }^{3}$, most of the data that are used for SDG reporting continue to consist of traditional data collected by national statistical offices (NSOs), government ministries and international organisations and are often costly to obtain, infrequently collected, reported at the national level and not always considered to be most accurate, open or offering complete coverage $^{4-6}$.

This has led to increased calls for the inclusion of the full range of actors involved in urban data production in order to inform the design, implementation and monitoring of sustainable urban strategies through urban knowledge that is inclusive and relevant to local needs ${ }^{7}$. In a similar vein, researchers have called for the inclusion of non-traditional data sources into reporting mechanisms on the SDGs ${ }^{8}$. Citizen science, or 'the involvement of citizens in scientific research and/or knowledge production ${ }^{4}$, can be especially of value in contexts where funding for improving national statistical capacity is restricted, while providing alternative methodologies and data sources for indicators that do not yet have established methodologies or regularly produced data.

In spite of the relevance and potential of more inclusive and non-traditional modes of urban knowledge and data production for SDG monitoring and implementation in Africa, this remains an understudied area of research, which so far has mainly been applied in the environmental field ${ }^{9-11}$. Moreover, few studies have had a specific urban focus, although this is changing as part of a growing interest in trans-disciplinary research approaches that advance the co-production of knowledge between scientists and society for urban sustainability ${ }^{12-14}$.

This Perspective builds on this emerging body of work to reflect on the use and usefulness of citizen generated data for SDG planning and reporting in urban Africa by drawing on research conducted between August 2018 and November 2019 in the cities of Luanda, Angola and Maputo, Mozambique. By working with research teams composed of researchers, practitioners, local leaders, community members and university students, the research collected both quantitative and qualitative data on a selected number of indicators of the urban SDG in three settlements in each city with the aim of using these data to inform more inclusive, sustainable and participatory urban planning and policymaking. More concretely, the project aimed to contribute to the establishment of a methodology and baseline for the implementation and monitoring of SDG 11 and related urban policies, and the creation and strengthening of mechanisms of local knowledge (co-) production and experience sharing among different actors and stakeholders within, as well as between the two cities.

The paper starts by providing an overview of the challenges around the monitoring of SDG 11 before introducing the cities and outlining the methodology underpinning the research project. It then presents the study's key findings and results, and concludes with reflections on the challenges and opportunities for meeting SDG 11 in African cities.

\footnotetext{
${ }^{1}$ African Centre for Cities, University of Cape Town, Cape Town, South Africa. ${ }^{2}$ Development Workshop, Luanda, Angola. ${ }^{3}$ Centre for Policy Analysis (CAP), Eduardo Mondlane University, Maputo, Mozambique. ${ }^{凶}$ email: sylviacroese@gmail.com
} 
Box 1 SDG indicator classification by tiers

Tier 1: Indicator is conceptually clear, has an internationally established methodology and standards are available, and data are regularly produced by countries for at least 50 percent of countries and of the population in every region where the indicator is relevant.

Tier 2: Indicator is conceptually clear, has an internationally established methodology and standards are available, but data are not regularly produced by countries.

Tier 3: No internationally established methodology or standards are yet available for the indicator, but methodology/standards are being (or will be) developed or tested.

The global indicator framework for the SDGs was developed by the Inter-Agency and Expert Group on SDG Indicators (IAEG-SDGs), established in March 2015 and composed of member states and regional and international agencies as observers, and adopted by the UN General Assembly on 6 July 2017 (A/RES/ 71/313).

In one of its early proposed iterations, the tier classification contained 81 Tier 1 indicators, 57 Tier 2 and 88 Tier 3 indicators, with 4 indicators having multiple tiers (different components of the indicator classified into different tiers), with a total of 230 unique indicators (out of a total 241 indicators excluding nine repeated indicators under different targets). Through periodic annual reviews, the tier classification was gradually adjusted. The latest changes to the framework followed a '2020 comprehensive review' conducted by the IAEGSDGs and their approval at the 51st session of the UN Statistical Commission of March 2020.

As of 17 July 2020 the updated tier classification no longer contains Tier 3 indicators, but instead 123 Tier I indicators, 106 Tier II indicators and 2 indicators that have multiple tiers, although the tier classification of the newly updated indicators remain provisional until a full data availability review is conducted. Source: https://unstats.un.org/sdgs/indicators/indicators-list/ and https://unstats. un.org/sdgs/iaeg-sdgs/tier-classification/.

\section{MEETING SDG 11}

The inclusion of a stand-alone goal on the need to turn cities and human settlements more inclusive, safe, resilient and sustainable as part of the 17 SDGs, and their overarching set of corresponding targets and indicators was part of a contested process that sought to address some of the shortcomings of the Millennium Development Goals (MDGs) — which were formulated largely in a technical and top-down fashion and only applied to developing countries $^{15,16}$. The success of its inclusion illustrates the global policy shift that recognises cities-beyond slums-as important sites, drivers and systems of sustainable development in an increasingly urban world. At the same time, it masks important differences in understandings of 'why and how cities matter, what should be done to advance the urban agenda, why cities matter for sustainability, and indeed what defines a city in the first place $^{\prime 17,18}$. While experts contributing to the UN Open Working Group on SDG 11 highlighted that successful implementation would depend on 'multi-scalar system[s] of reporting and monitoring [...] built from local, city and regional government processes $^{\prime 19}$, so far SDG 11 reporting and monitoring systems remain largely national exercises, which are often not linked to subnational processes ${ }^{20}$.

SDG 11 expands the focus of the MDGs' emphasis on basic services and slum reduction to cover a broader aspect of provision of basic services, such as waste management, transport and public spaces, which are covered by ten targets: seven outcome-oriented and three process-oriented ones (see Table 1).

In spite of the comprehensive scope of the goal and its corresponding targets and indicators, a pilot project studying the indicators of the urban SDG in the run up to its adoption in five cities across the world (including Cape Town and Kisumu in Africa) showed that in none of the cities a single draft indicator was regarded as both important or relevant and easy to report on in terms of data availability ${ }^{21,22}$. Particular challenges were noted with regard to engaging with and measuring informality, particularly in relation to the indicators related to informal settlements, transport and waste management ${ }^{23}$. Findings of a follow-up research project confirm persisting challenges related to the monitoring and reporting of SDG 11 indicators, even after their revision. These include target vagueness and lack of clarity, and hence measurability, as well as questions around the appropriateness and usability of corresponding indicators to measure and report on progress ${ }^{24}$. Indeed, to date, out of a total of 15 indicators only two indicators of SDG 11 have been confirmed as Tier I. Moreover, it took until 2019 for most other indicators to be upgraded from Tier III to Tier II indicators, meaning that while progress has been made on methodologies for the majority of indicators of the goal data are still not regularly produced (see Table 1). The UN has confirmed that 'the data gaps on SDG 11 are particularly large 25,26 .

These gaps and challenges point to the important distinction between the double function of SDG indicators or the difference between indicators used as 'report cards' or as management tools ${ }^{27}$. An excessive focus on the report card function of the indicators can lead to technocratic governance by numbers instead of their use as a planning tool for real-world problem solving ${ }^{27,28}$. This illustrates the big conundrum surrounding the SDGs more generally and their purpose on the one hand as a universal comparable monitoring and reporting framework vs. the need to localise this framework so that it becomes useful and relevant to local planning and implementation processes, which are by nature complex and diverse.

In response, a number of cities across the world have started processes to adapt and localise SDG indicators to their local context. These include cities such as Bristol and Los Angeles that have undertaken this work as part of the Local Data Action Solutions Initiative (LDA-SI), a joint effort between the Sustainable Development Solutions Network's Thematic Research Network on Data and Statistics and the USA Sustainable Cities Initiative (https://www.sdsntrends.org/local-data-action). However, most cities-especially small but rapidly growing ones-in Africa lack the support, capacity or even mandate to collect and manage data in line with existing (largely informal) local contexts ${ }^{29}$. This in turn reinforces existing hegemonic forms of urban knowledge production through which African cities remain largely invisible and unrecorded ${ }^{30,31}$.

Existing data weaknesses do not just apply to local capacity to generate data, but also to the lack of participatory platforms and mechanisms through which data can be shared and used for planning in context-specific ways. Research on Tanzania shows for instance how the SDG reporting process is dominated by national government with more concern for global reporting than local implementation $^{32}$. Collaborative data efforts involving multiple actors and stakeholders, including local citizens themselves, can contribute to filling this gap from the bottom-up, not just by generating the necessary data, but also by turning the monitoring process more inclusive and transparent ${ }^{33}$.

\section{LUANDA AND MAPUTO}

The need to make cities in Angola and Mozambique more inclusive, safe, resilient and sustainable is undisputed. Both countries have a history of armed conflict and rapid urbanisation, resulting in the growth of vast informal settlements, especially in the capital cities. Angola's capital city of Luanda now counts over 7 million inhabitants, while the population of the city of Maputo, surrounded by a rapidly growing city region of about 2 million, is over 1 million, representing a more than tenfold multiplication in Luanda and a doubling of the population in the case of Maputo since both countries reached independence from Portugal in $1975^{34,35}$. In both cities, post-colonial policies and planning have reinforced existing socio-spatial inequalities ${ }^{36}$.

While both countries are signatory to the 2030 Agenda and other global urban commitments and high-level references have been made in government discourse and planning to these commitments, there is little local awareness of the SDGs. National SDG localisation efforts, such as development planning alignment, 
Table 1. SDG 11 targets, indicators and current tier classification.

Goal 11. Make cities and human settlements inclusive, safe, resilient and sustainable

Target Indicator Tier classification

11.1 By 2030, ensure access for all to adequate, safe and affordable housing and basic services and upgrade slums

11.1.1 Proportion of urban population living in Tier I slums, informal settlements or inadequate housing

11.2 By 2030, provide access to safe, affordable, 11.2.1 Proportion of population that has accessible and sustainable transport systems for convenient access to public transport, by sex all, improving road safety, notably by expanding age and persons with disabilities public transport, with special attention to the needs of those in vulnerable situations, women, children, persons with disabilities and older persons

11.3 By 2030, enhance inclusive and sustainable urbanisation and capacity for participatory, integrated and sustainable human settlement planning and management in all countries

11.3.1 Ratio of land consumption rate to population growth rate

11.3.2 Proportion of cities with a direct participation structure of civil society in urban planning and management that operate regularly and democratically

11.4 Strengthen efforts to protect and safeguard 11.4.1 Total per capita expenditure on the the world's cultural and natural heritage preservation, protection and conservation of all cultural and natural heritage, by source of funding (public, private), type of heritage (cultural, natural) and level of government (national, regional, and local/municipal)

11.5 By 2030, significantly reduce the number of 11.5.1 Number of deaths, missing persons and deaths and the number of people affected and directly affected persons attributed to disasters substantially decrease the direct economic losses per 100,000 population

relative to global gross domestic

product caused by disasters, including waterrelated disasters, with a focus on protecting the poor and people in vulnerable situations

11.5.2 Direct economic loss in relation to global Tier II

GDP, damage to critical infrastructure and number of disruptions to basic services, attributed to disasters

11.6 By 2030 , reduce the adverse per capita environmental impact of cities, including by paying special attention to air quality and municipal and other waste management

11.7 By 2030, provide universal access to safe, inclusive and accessible, green and public spaces, in particular for women and children, older persons and persons with disabilities

11.a Support positive economic, social and environmental links between urban, peri-urban and rural areas by strengthening national and regional development planning

11.b By 2020, substantially increase the number of cities and human settlements adopting and implementing integrated policies and plans towards inclusion, resource efficiency, mitigation and adaptation to climate change, resilience to disasters, and develop and implement, in line with the Sendai Framework for Disaster Risk Reduction 2015-2030, holistic disaster risk management at all levels

11.6.1 Proportion of municipal solid waste collected and managed in controlled facilities out of total municipal waste generated, by cities 11.6.2 Annual mean levels of fine particulate matter (e.g., PM2.5 and PM10) in cities (population weighted)

11.7.1 Average share of the built-up area of cities Tier II that is open space for public use for all, by sex, age and persons with disabilities

11.7.2 Proportion of persons victim of physical Tier II or sexual harassment, by sex, age, disability status and place of occurrence, in the previous 12 months

11.a.1 Number of countries that have national urban policies or regional development plans that (a) respond to population dynamics; (b) ensure balanced territorial development; and (c) increase local fiscal space

11.b.1 Number of countries that adopt and implement national disaster risk reduction strategies in line with the Sendai Framework for Disaster Risk Reduction 2015-2030

11.b.2 Proportion of local governments that adopt and implement local disaster risk reduction strategies in line with national disaster risk reduction strategies

11.c Support least developed countries, including through financial and technical assistance, in building sustainable and resilient buildings utilising local materials develop a suitable replacement for the 2025 comprehensive review

Source: UNDESA Stats division, see https://unstats.un.org/sdgs/iaeg-sdgs/tier-classification/. 
data mapping exercises, baseline studies and the development of a Voluntary National Review (VNR) (submitted in 2020 by Mozambique and planned for 2021 by Angola) have been largely led and supported by UN agencies.

Data on informal settlements is scarce in both countries, often limited to the quantitative measurement of access to basic services such as water and electricity, and generally is not collected, managed or monitored in a participatory and accountable manner. Notably, in Angola only one nation-wide census has been conducted since independence and the data available from this census (final results disseminated in 2016) are not disaggregated by gender, age, or disability as per required in SDG reporting, although a recent survey on expenditure, income and employment conducted in 2018-2019 offers more detailed information $^{37}$. The latest census conducted by the Mozambican NSO in 2017 is more detailed in that respect and most of this information is freely accessible online (http://www.ine.gov.mz/ivrgph-2017). Nevertheless, both countries face significant gaps when it comes to the data required to report on the SDGs. Initial baseline studies indicated that Angola has data to report on $41 \%$ of the total of SDG indicators ${ }^{38}$, while in Mozambique this stands at $38 \%$, with data for another $12 \%$ partially being collected ${ }^{39}$. These challenges play out when looking at the data available to report on SDG 11 indicators with most data either not or only partially available, outdated or simply not reported (see Table 2).

Apart from the lack of available data, there are also few mechanisms to publicly share existing data or for collaboration around data among line ministries, with local governments or other institutions that operate in the urban space, such as for instance utility companies. In Mozambique, the many international organisations and donors also add to a fragmented data landscape. Overall, data collection and reporting is considered to be the prerogative of the NSO and development policies continue to be planned at the central government level and then cascaded down through line ministries. Policies tend to follow an inputoutput logic, through the identification of quantitative deficits and corresponding targets to address them, with little regard for their qualitative or spatial dimension.

\section{CO-PRODUCING URBAN KNOWLEDGE}

In order to address the existing lack of urban data production and sharing for SDG 11 monitoring and implementation, the research took a collaborative approach in the sense that the project sought to work with government and contribute to filling existing knowledge gaps ${ }^{40}$. Throughout the research process, principles commonly agreed as contributing to high-quality knowledge coproduction were followed, such as a focus on the importance of context, a recognition of multiple ways of knowing and doing, working towards set goals and on-going learning, interaction and engagement among the different actors involved ${ }^{41}$.

This meant that the research teams engaged as many relevant urban stakeholders as possible. In the inception phase of the research this involved the engagement of stakeholders in the codesign of the research survey questions with the added aim of gaining support and buy in for the research. In Luanda, such stakeholders included government officials, representing the Angolan NSO, the Urban Upgrading Office for Luanda (GTRUCS), the Ministry of Planning and Housing, as well as local NGO representatives, academia and local UN representatives. In Maputo, these included government officials, specifically the SDG focal persons appointed within the Ministry of Economy and Finances and the NSO, the National Association of Mozambican Municipalities (ANAMM), as well as local UN representatives.

At the community level, research teams in both cities consisted of representatives of local residents' committees, community members as well as university students who participated in research trainings and participatory mapping exercises, as well as the data collection and validation. In Luanda, the research was coordinated by practitioners of Development Workshop Angola, an NGO with long-standing experience of working in and with local communities in areas ranging from infrastructure to basic services, land and housing through research, practice and advocacy. In Maputo, the work was led by researchers from the Centre for Policy Analysis of Eduardo Mondlane University, which specialises in studying migration, gender, food security and climate change and the linkages between them in Maputo.

In both cities, three self-built settlements were selected. This type of settlement represents the home of the majority of, mostly low income, urban dwellers, as opposed to the wealthier who live in the small core of planned and formally laid-out houses and apartment buildings in either the city centre or selected suburbs. Self-built settlements may vary in terms of their location, built environment and levels of access to basic services, ranging from more recently and precariously built settlements located further out in the periphery to more consolidated and better serviced settlements closer to the city centre. The research sample was chosen to reflect a cross section of this variation through the selection of three settlements with similar typologies in each city: an old settlement dating back to colonial times, a more recently built or expanded settlement and a settlement that had undergone urban upgrading. Within each settlement (with an average of about 24,000 residents each), households were randomly selected, with local sample sizes being partly determined by time and resource considerations and constraints. In Luanda these settlements respectively were $\mathrm{Km} 12 \mathrm{~A}(n=310)$ in the district of Estalagem, Viana, Nova Urbanização $(n=148)$ in Cacuaco Vila, Cacuaco, and Cariango $(n=224)$ in Tala Hadi, Cazenga. In the municipality of Maputo these were Luís Cabral $(n=200)$, Hulene B $(n=200)$ and Chamanculo $C(n=200)$, all together representing a total of 1282 households. While a more precisely stratified sample (weighted using census data on population per settlement type) would be needed for the results to be more widely representative of the cities, the method and results can be seen as representative of the settlements sampled and sufficient and appropriate for meeting the purpose of exploring challenges and opportunities related to SDG 11 data monitoring and implementation.

Tablets were used to conduct the surveys, which were processed using the online application Kobotoolbox and the free and open source software Open Data Kit (ODK). In each neighbourhood, interviews and focus groups were also held before (in the case of Maputo) and/or after (in the case of Luanda) the completion of the survey data collection to collect qualitative and more in-depth data about the settlements. Moreover, in each of the six neighbourhoods the survey findings were presented and discussed with local administrations and those who had participated in the research with a view of triangulating, validating and clarifying unexpected results or queries before proceeding to their analysis, presentation and dissemination to national government level and other relevant stakeholders. Ethical clearance for the research was obtained from the Faculty of Engineering and the Built Environment of the University of Cape Town and local research participation was based on informed consent.

The survey included basic household questions and specific questions related to a selected number of targets and indicators of SDG 11. Particular attention was paid (but not limited) to targets with indicators (at the time of research) classified as Tier II or III, and included target 11.1 (housing and basic services); target 11.2 (transport systems for all); target 11.3 (participatory planning and management); target 11.6 (air quality and waste management) and target 11.7 (green public spaces). Many of the questions focused on citizen's perceptions and experiences of these issues and services, with a view to devising indicators that reflect urban sustainability in people's own terms ${ }^{42}$. 
Table 2. SDG 11 indicator data availability for Angola and Mozambique.

Goal 11. Make cities and human settlements inclusive, safe, resilient and sustainable

Available with

Line National

Indicator
11.1.1 Proportion of urban population living in slums, informal settlements or
inadequate housing
11.2.1 Proportion of population that has convenient access to public transport, by
sex, age and persons with disabilities
11.3.1 Ratio of land consumption rate to population growth rate
11.3.2 Proportion of cities with a direct participation structure of civil society in urban
planning and management that operate regularly and democratically

11.4.1 Total expenditure (public and private) per capita spent on the preservation, protection and conservation of all cultural and natural heritage, by type of heritage (cultural, natural, mixed and World Heritage Centre designation), level of government (national, regional and local/municipal), type of expenditure (operating expenditure/ investment) and type of private funding (donations in kind, private non-profit sector and sponsorship)

11.5.1 Number of deaths, missing persons and directly affected persons attributed to disasters per 100,000 population

Partially available (2015)

11.5.2 Direct economic loss in relation to global GDP, damage to critical infrastructure and number of disruptions to basic services, attributed to disasters

11.6.1 Proportion of municipal solid waste collected and managed in controlled facilities out of total municipal waste generated, by cities

Availability

Partially available

Not available

Available (2016)

Partially available (2016) Not reported

11.6.2 Annual mean levels of fine particulate matter (e.g., PM2.5 and PM10) in cities Not reported (population weighted)

11.7.1 Average share of the built-up area of cities that is open space for public use for Not available all, by sex, age and persons with disabilities

11.7.2 Proportion of persons victim of physical or sexual harassment, by sex, age, disability status and place of occurrence, in the previous 12 months

11.a.1 Number of countries that have national urban policies or regional development plans that (a) respond to population dynamics; (b) ensure balanced territorial development; and (c) increase local fiscal space

11.b.1 Number of countries that adopt and implement national disaster risk reduction Not reported strategies in line with the Sendai Framework for Disaster Risk Reduction 2015-2030

11.b.2 Proportion of local governments that adopt and implement local disaster risk Not reported reduction strategies in line with national disaster risk reduction strategies Not available

Partially available (2017)

Not reported

Partially available (2016) some effort

Available

Available with Line Line Line ministries ministries

ministry

Available with great effort

Available with Line great effort ministry

Not reported

Not reported UN Habitat

Available

Available
Line ministries

Line ministries

Source: adapted from National Statistics Institutes of Angola (INE, 2018) and Mozambique (INE, 2019).

\section{RESEARCH FINDINGS}

The following sections provide an overview of the data collected $^{43-45}$ for each indicator alongside summarised research findings. As the indicators for targets such as 11.2 and 11.7 include a disaggregation between the proportion of the population by sex, age and persons with disabilities we sought to make similar distinctions in our analysis.

In this regard, the gendered socio-economic profile of the neighbourhoods studied in both cities must be noted. Women represented the majority of respondents across the research samples: $55 \%$ in Luanda and $70 \%$ Maputo. Our findings indicate that levels of income were low among both men and women, with $70 \%$ of participants in Maputo reporting an income of under USD 70 a month or about USD2 a day and $49 \%$ of participants in Luanda reporting an income of USD 20 a month or less than USD 1 a day (converted from local currencies at exchange rates at the time of research). Levels of unemployment were also high across the neighbourhoods studied in both cities, with $40 \%$ in Luanda and $60 \%$ of respondents in Maputo reporting to not have any kind of job. However, across the board income levels were generally lower among women while unemployment levels were substantially higher. While the possible over-representation of women in the samples can partly be explained due to the fact that most of the survey work was conducted during the week when those working were absent from home, these findings are in line with national census and survey data on income and unemployment in both countries.

This confirms many calls around the gendered nature of development and the potential of gender equality as an accelerator for achieving the SDGs ${ }^{46}$. However, our findings also point to the importance of age, with young people in the 18-29 year age bracket reporting as generally being higher educated but more often unemployed. The elderly on the other hand seemed more vulnerable, for instance in terms of feelings of safety, but at the same time were more active in local participation structures in their neighbourhoods. Only $6 \%$ of the research participants in Luanda and $4 \%$ in Maputo had some kind of disability, making it difficult to make any conclusive conclusions about the findings for this part of the population, although care was taken to include as many people with disabilities in the community focus groups. Taken together, these findings highlight the importance of data and respective interventions to reflect and build on the diversity 
of the urban experience of different population groups so as to leave no one behind.

\section{Target 11.1 Housing and basic services}

We collected data on access, quality, safety and affordability of housing and basic services by asking how people had accessed their housing, how they perceived the state of their houses and if they conducted maintenance, their main source for accessing basic services such as water, what they paid for these services and how they perceived access and quality.

In the neighbourhoods sampled in both cities, about a third of participants in each settlement had built their houses themselves, while the second most common mode of access was the purchase in Luanda and inheritance in Maputo of previously self-built houses. A minority of participants (2\% in Luanda and $9 \%$ in Maputo) had some kind of formal document issued by the state to prove their ownership of the house, with most participants $(59 \%$ in Luanda and $43 \%$ in Maputo) relying on a declaration -received from the previous house owner or occupier of the land (as the state in both countries owns all land) and/or approval from local community leaders. While the UN considers lack of secure tenure, one of the main characteristics of a slum or informal settlement (together with lack of access to improved water; access to improved sanitation facilities; sufficient-living area; and durable housing) we found that in the areas studied in both cities there is no correlation between tenure status and access to basic services. This was especially the case in Maputo, where on average $85 \%$ of participants had access to basic services such as water through a tap at home, even in the more precariously built and densely populated areas where residents lacked formal tenure, against an average of $51 \%$ in Luanda. Upgrading interventions did improve access to basic services in Luanda, with residents of an upgraded neighbourhood having gained almost universal access to water at home, compared to less than $10 \%$ in another neighbourhood, although levels of formal tenure were equally low in both places. This raises questions about the usefulness of using the proportion of the urban population living in informal settlements as an indicator for measuring access to housing and basic services.

The data collected on basic services in turn show how important it is to take levels of adequacy, safety and affordability into account in order to measure effective access. For instance, the data on access to water shows how water in the areas studied is often only available during certain hours of the day, perceived as of dubious quality (especially in the neighbourhoods in Luanda, where on average $89 \%$ treats water with the use of household bleach before consumption) and of high cost. In Maputo, where water provision has been privatised, many residents in the settlements studied have been cut off from the grid after having fallen behind on payments and as a result have come to rely on their neighbours for access to water, using hoses to pump water to their houses and paying them a nominal fee. This experience was echoed in Luanda, where a member of a community that had recently been connected to the water and electricity grid commented: 'we are connected to the grid, but we don't have money to charge our pre-paid metres'. As a result, illegal connections are rife while residents in areas where service provision is unstable end up relying on informal service providers, while still being billed by the government, significantly increasing the effective cost of water consumption.

\section{Target 11.2 Transport systems for all}

We collected data on distance/time to access public transport, cost of use of transport and whether people felt safe using transport and compared this across different population groups. The major finding was that the degree of access to transport is predominantly determined by economic factors. Owing to high levels of poverty and unemployment very few participants actually reported using public transport (eg. 20\% in Maputo), with one research participant in Maputo noting that 'we live on the basis of lifts'. Moreover, those who do use transport mainly rely on informal transport systems (mini buses or motorcycles or a combination of both) for their daily transport, rather than public transport systems, which have limited capacity and coverage across the city.

In terms of the costs involved when accessing these transport systems, daily expenses in the areas studied are on average USD2 a day and increase as the distance to the city centre increases, which is high considering reported income levels. Distance or time to access nearest access points generally does not surpass $500 \mathrm{~m}$ or a 15 min walk, with motorcycles in Luanda often functioning as feeder systems connecting secondary to main roads, and was therefore not considered a limiting factor. The quality of roads on the other hand was seen as an important barrier to accessing transport, with participants in a focus group in Luanda stating that: 'when it rains, taxis cannot enter into our neighbourhood [...] we can only speak of public transport when our roads are in a better state'.

The diversity of experiences in terms of convenience of access to transport by sex, age and persons with disabilities in turn becomes clear when looking at reported feelings of safety. In Maputo, $56 \%$ of participants in the selected settlements reported not feeling safe using transport, against $32 \%$ in Luanda. This lack of safety was explained by the lack of public illumination, a lack of police patrolling, combined with high levels of local crime, making the use of transport dangerous, especially in the early and late hours of the day, which is when most require transport. Notably, there were no significant differences in reported feelings of safety between men and women in the areas studied (57\% women vs. $56 \%$ men in Maputo and $36 \%$ women vs. $28 \%$ men in Luanda), but there were differences between the young and the elderly, with those over 50 years old feeling more unsafe. Persons with disabilities generally felt left out, as informal transport systems in neither of the cities offer special seats for people with disabilities. While public transport buses may have some special seats, participants with disabilities in Luanda noted that as their routes are limited and buses often overloaded they did not make use of them.

\section{Target 11.6 Air quality and waste management}

In both cities, there are no publicly available data on annual mean levels of particulate matter, a common challenge across cities in the world ${ }^{47}$. While there are examples of successful citizen monitoring of levels of particulate matter in informal settlements in Africa ${ }^{48}$, the use of tablets to generate data on these levels was out of reach in this project. Data were instead collected on levels and frequency of waste collection, as well as on local perceptions of environmental issues.

In terms of waste collection, significant differences were reported between the areas studied in the two cities, which provides some insight into the varying proportions of municipal solid waste that are centrally collected and managed. In the areas studied in Maputo, waste collection was relatively regular-with $62 \%$ of participants reporting collection to take place more than once a week, but with wide variations in terms of levels of waste collection across the neighbourhoods, ranging from $93 \%$ to $58 \%$. In Luanda, waste collection services in the areas studied were far worse, with $76 \%$ of participants reporting that there was no effective central system of waste collection. There was also wider variation in experiences of levels of waste collection across the neighbourhoods studied, varying between $70 \%$ and $19 \%$. In the neighbourhoods with the lowest collection levels, participants stated that they would burn or bury their waste or deposit the waste in informal waste dumps in the neighbourhood.

Notably, while air pollution came up in relation to the smells of informal waste dumps, when asked about pollution and related concerns, many participants in the settlements studied in both cities referred to noise pollution, such as loud music during parties 
or neighbourhood gatherings, rather than environmental pollution, as being a major nuisance and a source of frequent community conflict.

Interventions to improve local environmental awareness are few, with $89 \%$ of the participants in the settlements studied in Luanda and $83 \%$ in Maputo reporting never having attended an activity on issues related to the environment. Where such activities had taken place, they were generally led by local community leaders or in the case of Maputo by the National Disaster Management Institute, the disaster relief agency of Mozambique, in relation to local floods. In both cities, flooding was reported as the main environmental concern, affecting communities in all of the neighbourhoods that were part of the study, especially during the rainy season, due to a lack of basic sanitation, drainage and sewage systems. Part of one of the neighbourhoods studied in Maputo had been permanently flooded since 2000 .

\section{Target 11.7 Green and public spaces}

Data were collected on the existence, use and levels of satisfaction of local public spaces and analysed according to gender and age, while data on the proportion of persons victim of physical or sexual harassment were not collected as these were seen to require research methods and expertise that were beyond the scope of the project.

In both cities, all of the neighbourhoods that were part of the study lack public spaces, with most public parks dating back to colonial times and located mainly in the historical colonial city centre. Maputo fared better compared to Luanda, with $64 \%$ of participants reporting to have public spaces in their neighbourhoods compared to $82 \%$ of participants in Luanda reporting not having any public spaces.

Many areas of leisure that exist in the settlements studied in Luanda are private spaces that charge entrance fees. In the neighbourhood in Luanda that had benefitted from upgrading interventions, these had mostly focused on the improvement of infrastructure (housing, sanitation and roads) and did not incorporate the development of green or public spaces, with the few acacia trees found in the neighbourhood reported to have been planted in colonial times. In the upgraded neighbourhood studied in Maputo on the other hand the development of public spaces had been taken into account, most likely due to a stronger involvement of the donors that funded these interventions.

However, the existence of spaces contrasted with their reported use as well as levels of satisfaction, raising questions around the usefulness in this context of using average share of the built-up area of cities that is open space as an indicator to measure their safety, inclusivity and accessibility as experienced by different population groups. In Luanda, the majority of participants (87.5\%) in the areas studied reported feeling dissatisfied or highly dissatisfied with existing public spaces. Notably, use was higher among women compared to men, with $75 \%$ against $66 \%$ reporting to use existing spaces sometimes or often. In addition, use was lower among the elderly (age 70+) compared to those in the age group of 30 to 49 , with $67 \%$ of the former saying never to make use of existing spaces, against $77 \%$ of the 30 to 49 age group who stated to use the spaces with some regularity. Similar findings emerged in the studied settlements in Maputo where levels of satisfaction were also low, with $64 \%$ reporting feeling dissatisfied or highly dissatisfied with existing public spaces. Use of spaces in Maputo was somewhat higher among men compared to women, but also lower among the elderly compared to the youth.

In community focus groups and validation sessions, levels of use and satisfaction were explained through the lack of effective mechanisms for the maintenance and upkeep of existing spaces and the lack of involvement of community members in the implementation of initiatives. For instance, in Luanda a tree planting initiative literally died, due to a poor choice of the kind of trees that were planted and the lack of an irrigation plan. In some cases the use of available spaces was also said to be restricted because of concerns around safety, often caused by a lack of (working) street lights. Community members in Maputo reported having developed attempts to maintain existing public spaces but that these had failed as other community members were reluctant or unable to pay fees to fund such initiatives.

\section{Target 11.3 Participatory planning and management}

Considering the importance of direct participation structures of civil society in urban planning and management and the lack of qualitative data on this in both cities, our data collection focused on ascertaining which structures exist at the local level, how they operate and who participates in them by asking which institutions community members would turn to report any concerns pertaining to life in their neighbourhood.

In both cities, local community leadership structures that originate in early post-independence times are key to local governance. Peri-urban neighbourhoods tend to have structures with representatives at the block and quarter level that in turn are organised at the neighbourhood level through committees that report to the municipal council, which meets with some regularity. While the lines between these institutions and local ruling party structures are blurred, making it difficult to objectively assess how democratic they are, these structures often represent the main avenue for local participation and first port of call for the communication and resolution of residents' concerns, ranging from inheritance disputes to local crime. In the settlements studied in both cities, local leadership structures reported being in frequent contact with the local police and in Maputo also as being involved in local community initiatives, for instance around safety through community policing groups.

When comparing findings for gender, it is notable that in both cities these local structures are contacted more often by men than women. In Luanda, $56 \%$ of men reported to have contacted the local residents' committee sometimes or often, against $39 \%$ of women. In both cities, these levels were also much higher among those above 50 years old, compared to youth between 18 and 29 years. However, there were no significant differences in terms of levels of membership in these local committees between men and women, although more women than men reported to be active in other local organisations and structures, such as local churches and voluntary associations. Hence, our findings show that to achieve more participatory, integrated and sustainable human settlement planning and management, qualitative data is required that provides insight into existing local participation structures, their workings and who does and does not participate in them.

\section{CHALLENGES AND OPPORTUNITIES FOR MEETING SDG 11}

By using a collaborative approach, working together with local communities, leaders, practitioners and researchers in data collection on SDG 11, this project was able to co-produce knowledge that speaks to the specific local contexts of each city. The findings do not only highlight the importance of assessing the urban experience as it varies between different groups of the urban population, but also how they are manifested at the neighbourhood level and, therefore, the importance of paying attention to intra-urban spatial inequalities ${ }^{49}$.

Combining the collection of quantitative with qualitative data in an iterative way allowed for a more comprehensive understanding of the urban context in ways that the existing SDG monitoring framework and traditional forms of data collection do not account for. Importantly, it captured the important role of informal actors in providing public services, for instance in the area of transport, as well as of the role of community leadership structures in local urban management. It also surfaced unexpected findings, such as 
the constraints in accessing public services such as water, concerns around noise pollution or the contrast between the existence and use of/satisfaction with public spaces. As such, the research points to the importance of indicators on local perceptions in the monitoring of the quality and access to public services, as well as the need for complementary indicators, such as for instance the existence of (functioning) public illumination when assessing the safety of transport systems and public spaces.

Hence, although the focus of the research was on SDG 11 indicators, the findings inevitably point to the ways in which achieving the urban goal is deeply interlinked to the success in meeting other goals, ranging from gender (SDG 5) to poverty (SDG 1), decent employment (SDG 8) and infrastructure (SDG 9). In doing so, the research offers important lessons and evidence for the formulation and implementation of more integrated and sustainable urban (upgrading) policies and interventions, but also raises difficult questions and trade-offs around the government capacity available in African cities to do so.

Working in Portuguese speaking countries also raised the importance of language when localising what is meant to be a universally comparable monitoring and reporting framework. While the SDG indicator framework has been translated into a number of the UN's working languages, including Arabic, Chinese, French, Russian and Spanish, this does not include Portuguese. In engaging with the indicator framework we found that different indicator descriptions were used between Angola and Mozambique, with certain terms sometimes being domesticized (eg. the term slum using the local language term of 'musseque' by the Angolan NSO), while in other cases the term as used in Brazilian Portuguese would be used (e.g., the term 'favela' by the Mozambican NSO). This also speaks to the divergence between global criteria used to define slums, such as formal tenure, and the ways in which slums are locally understood and managed. As such, the research highlights the importance of localised understandings of the SDG targets and indicators and the need to critically interrogate, unpack and complement the language, concepts as well as assumptions that underpin the global SDG monitoring framework, as this not only affects universal comparability but also can have important local policy implications ${ }^{50}$.

Knowledge co-production inherently comes with risks and limitations that are political in nature and embedded in social relations, cultural assumptions and professional incentive structures ${ }^{51}$. In our research, this required continuous reflexivity in terms of our own role as researchers and practitioners, as well as the careful management and navigation of the interests and expectations of our research partners-especially when it came to balancing community and government inputs and participation. In both cities, local community leaders and residents welcomed the opportunity of being an integral part of a research project as partners rather than subjects. University students in turn indicated how the work had challenged some of the preconceptions they had about poor people and the kind of knowledge they hold, illustrating the potential of citizen science as an educational tool for the youth ${ }^{52,53}$. Local government interest and participation on the other hand was at times uneven and partly shaped by external pressures and events such as the local elections that took place in Maputo in October 2018, followed by national elections the year after.

Bringing both parts together provided important opportunities for the creation of spaces for knowledge production and sharing. For instance, in a workshop hosted by the Angolan NSO towards the end of the project, research members from the local communities challenged the official government data for SDG reporting presented on that occasion. Municipal government officials in turn confided not to have sufficient resources or capacity to incorporate or manage the data collected in a structured way, therefore welcoming the collaboration with other actors and stakeholders. Officials from the Angolan NSO on the other hand invoked technical and methodological constraints and the need to adhere to UN approved indicators and methodologies for their reluctance to incorporate the collected data into their own reports. These challenges echo experiences elsewhere of the difficulties and time it takes to build trust and legitimacy around citizen science and community-based monitoring efforts ${ }^{54}$, as well as the need for more guidance to urban managers and planners to build the required skills to manage and use data collected in and on informal settlements ${ }^{55}$.

With a view of overcoming such challenges, researchers have outlined a roadmap to integrating citizen science into the formal SDG reporting process, which includes activities around building trust for the use of citizen science by national agencies, the compilation of an inventory around good practices of citizen science, building existing policy frameworks to advocate for citizen science and promoting dialogue on data quality and management ${ }^{4}$. An unexpected opportunity emerged in that regard in our research in Mozambique, which in 2019 started preparing its first VNR on SDG progress for submission to the UN in 2020. Through on-going engagements with the government officials and consultants involved in the preparation of this report, the project's key research findings were included in the country's $\mathrm{VNR}^{56}$, as well as incorporated in a city level review on the SDGs developed by the National Association of Mozambican Municipalities (ANAMM) as part of the VNR process. ANAMM also facilitated the participation of members of the research team in a training on SDG localisation for Mozambican municipal government officials in Maputo, while presenting on the Mozambican experience during a research workshop in Luanda.

While it is difficult to gauge the extent to which the research methodology and data will be incorporated beyond reporting into further monitoring and planning efforts, the different elements of the research process contributed to raising more awareness about SDG monitoring and implementation among both communities and government officials. In doing so, the research contributed to opening up an important dialogue around urban data and the importance of more localised, inclusive and participatory approaches to data collection and policymaking.

\section{Reporting summary}

Further information on research design is available in the Nature Research Reporting Summary linked to this article.

\section{DATA AVAILABILITY}

The data generated and analysed during this study are described in the following data record: https://doi.org/10.6084/m9.figshare.13142768 ${ }^{43}$. The data are available (in Portuguese) via DataFirst, the only African open access research data service and repository: https://www.datafirst.uct.ac.za/dataportal/index.php/catalog/central/about. Prospective users must register with DataFirst and agree to terms and conditions of use prior to being provided access to the data. The questionnaires, technical documents and reports that describe the survey process and the key results for 'Angola-Sustainable Cities Survey 2018, Luanda' are available at https://doi.org/10.25828/ed1q-2q8944, and for 'Mozambique-Sustainable Cities Survey 2019, Maputo' at https://doi.org/10.25828/acd7$7 \mathrm{q} 30^{45}$. The SDG indicator classification by tiers that underlie Box 1 in the related manuscript are publicly available at https://unstats.un.org/sdgs/indicators/indicators-list/ and https://unstats.un.org/sdgs/iaeg-sdgs/tier-classification/. The SDG 11 Targets, indicators and current tier classification that underlie Table 1 in the related manuscript are publicly available at https://unstats.un.org/sdgs/iaeg-sdgs/tier-classification/. Access to the original sources of the SDG 11 indicator data availability, which underlie Table 2 in the related manuscript, for Angola are publicly available at https://www.ine.gov.ao/images/ Populacao_Sociedade/Relatorio_ODS_FINAL.pdf and for Mozambique can be requested from the corresponding author, Sylvia Croese (sylviacroese@gmail.com).

Received: 2 June 2020; Accepted: 28 November 2020; Published online: 23 February 2021 


\section{REFERENCES}

1. Woolfrey, L. How data-ready are governments to monitor SDG progress? An assessment of socioeconomic data for SDG planning and reporting in Egypt, Zambia and Zimbabwe. Paper submitted for presentation at the Economic Research Forum's 26th Annual Conference, March 29-31, 2020. https://erf.org.eg/ publications/how-data-ready-are-governments-to-monitor-sdg-progress-anassessment-of-socioeconomic-data-for-sdg-planning-and-reporting-in-egyptzambia-and-zimbabwe/ (2020).

2. UNECA. Africa Sustainable Development Report. Tracking progress on Agenda 2063 and the Sustainable Development Goals. (AU, UNECA, AfDB and UNDP, 2017).

3. IEAG. A World that Counts. Mobilising the Data Revolution for Sustainable Development (IEAG Secretariat, 2014).

4. Fritz, S. et al. Citizen science and the United Nations Sustainable Development Goals. Nat. Sustain. 2, 922-930 (2019).

5. Jerven, M. How much will a data revolution in development cost?, For. Dev. Stud. 44, 31-50 (2017)

6. MacFeely, S. The 2030 Agenda: An Unprecedented Statistical Challenge. http:// library.fes.de/pdf-files/iez/14796.pdf (Friedrich Ebert Stiftung, Berlin, 2018).

7. Robin, E., Steenmans, K. \& Acuto, M. Harnessing inclusive urban knowledge for the implementation of the New Urban. Agenda. Urb. Res. Pract. 12, 137-155 (2017).

8. Hsu, A., Malik, O., Johnson, L. \& Esty, D. C. Development: mobilize citizens to track sustainability. Nature 508, 33-35 (2014).

9. Rufino, M. et al. Citizen scientists monitor water quantity and quality in Kenya. CIFOR Inf. Br., https://doi.org/10.17528/cifor/007013 (2018).

10. Pocock, M. et al. Developing the global potential of citizen science: assessing opportunities that benefit people, society and the environment in East Africa. $J$. Appl. Ecol. 56, 274-281 (2019).

11. Campbell, J. et al. The role of combining national official statistics with global monitoring to close the data gaps in the environmental SDGs. Stat. J. IAOS 36 , 443-453 (2020)

12. Polk, M. Co-producing knowledge for sustainable cities: joining forces for change (Routledge, 2015)

13. MacClune, K. et al. in Urban Planet: Knowledge Towards Sustainable Cities (eds. T. Elmqvist et al.) 239-259 (Cambridge University Press, 2018).

14. ICS. Advancing the 2030 Agenda in African Cities through Knowledge Co-production: Urban Experiments Led by Early-career African Scientists. https://council.science/ wp-content/uploads/2020/04/LIRA-2030-report-2020-04-29.pdf (ICS, Paris, 2020).

15. Fukuda-Parr, S. From the Millennium Development Goals to the Sustainable Development Goals: shifts in purpose, concept, and politics of global goal setting for development. Gend. Dev. 24, 43-52 (2016).

16. Klopp, J. M. \& Petretta, D. L. The urban sustainable development goal: Indicators, complexity and the politics of measuring cities. Cities 63, 92-97 (2017)

17. Barnett, C. \& Parnell, P. Ideas, implementation and indicators: epistemologies of the post-2015 urban agenda. Environ. Urban. 28, 87-98 (2016).

18. Parnell, S. Defining a global urban development agenda. World Dev. 78, 529-540 (2016).

19. Revi, A., Simon, D., Parnell, S. \& Elmqvist, T. Consultation on the UN Open Working Group on the SDGs' Urban SDG Goal 11: Targets \& Indicators. Confidential Draft for Review and Discussion. Royal Holloway, London 22-24 August 2014. https://www. africancentreforcities.net/wp-content/uploads/2015/01/LondonSDGCampaign _redraft_of_the_SDG-Goal11_Sustainable-CitiesHuman_Settlements_V4160914_.pdf (2014)

20. UCLG. The Localization of the Global Agendas. How Local Action Is Transforming Territories and Communities. Fifth Global Report on Decentralization and Local Democracy. (UCLG, 2019).

21. Simon, D. et al. Developing and testing the Urban Sustainable Development Goal's targets and indicators-a five-city study. Environ. Urban. 28, 49-63 (2016).

22. ODI. Projecting Progress: Are Cities on Track to Achieve the SDGs by 2030? Executive Summary. (ODI, 2016)

23. Arfvidsson, H., Simon, D., Oloko, M. \& Moodley, N. Engaging with and measuring Informality in the proposed urban sustainable development goal. Afr. Geogr. Rev. 36, 100-114 (2016)

24. Valencia, S. et al. Adapting the sustainable development goals and the new urban agenda to the city level: initial reflections from a comparative research project. Int. J. Urb. Sust. Dev. 11, 4-23 (2019).

25. UNECA. Africa Sustainable Development Report: Towards A Transformed and Resilient Continent. (AU, UNECA, AfDB and UNDP, 2018).

26. UN Habitat. Tracking Progress Towards Inclusive, Safe, Resilient and Sustainable Cities and Human Settlements. SDG 11 Synthesis Report, High Level Political Forum 2018. (UN Habitat, 2018).

27. Hansson, S., Arfvidsson, H. \& Simon, D. Governance for sustainable urban development: the double function of SDG indicators. Area Dev. Policy 4, 217-235 (2019)
28. Davis, K., Fischer, A. Kingsbury, B. \& Merry, S. E. Governance by Indicators: Global Governance through Quantification and Ranking. (Oxford University Press, 2012).

29. Borel-Saladin, J. Data dilemmas: availability, access and applicability for analysis in Sub-Saharan African cities. Urban For. 28, 333-343 (2017).

30. Robin, E. \& Acuto, M. Global urban policy and the geopolitics of urban data. Polit. Geogr. 66, 76-87 (2018)

31. Robinson, J. \& Parnell, S. The global urban: Difference and complexity in urban studies and the science of cities. in Sage Handbook of the 21st Century City (eds. Hall, S. \& Burdett, R.) 13-31 (Routledge, 2017).

32. Jönsson, K. \& Bexell, M. Localizing the sustainable development goals: the case of Tanzania. Dev. Pol. Rev. https://doi.org/10.1111/dpr.12497 (2020).

33. Saner, R., Yiu, L. \& Nguyen, M. Monitoring the SDGs: digital and social technologies to ensure citizen participation, inclusiveness and transparency. Dev. Pol. Rev. 38, 483-500 (2020).

34. INE Angola, Resultados Definitivos do Recenseamento Geral da População e da Habitação de Angola 2014 (INE Angola, 2016).

35. Censo 2017. IV Recenseamento Geral da População e Habitação (INE Mozambique, 2019).

36. Raposo, I. S., Jorge, S., Viegas, S. \& Melo, V. Luanda e Maputo: inflexões suburbanísticas da cidade socialista à cidade-metrópole neoliberal. Urbe. Rev. Bras. de Gest. Urban. 4, 189-205 (2012).

37. INE Angola. Inquérito Sobre Despesas E Receitas (IDR/IDREA) 2018-2019 (INE Angola, 2019).

38. INE Angola. Objectivos de Desenvolvimento Sustentável. Relatório sobre os Indicadores de Linha de Base Agenda 2030 (INE Angola, 2018).

39. INE Mozambique. Proposta de Quadro Nacional de Indicadores dos Objectivos de Desenvolvimento Sustentável de Moçambique (QNI) (INE Mozambique, 2019).

40. Conrad, C. C. \& Hilchey, K. G. A review of citizen science and community-based environmental monitoring: issues and opportunities. Env. Mon. Ass. 176, 273-291 (2011).

41. Norström, A. V. et al. Principles for knowledge co-production in sustainability research. Nat. Sustain. 3, 182-190 (2020).

42. Rydin, Y. Indicators as a governmental technology? The lessons of communitybased sustainability indicator projects. Environ. Plan. D: Soc. Space 25, 610-624 (2007).

43. Croese, S., Dominique, M. \& Raimundo, I. M. Metadata record for the manuscript: co-producing urban knowledge in Angola and Mozambique: towards meeting SDG 11. figshare https://doi.org/10.6084/m9.figshare.13142768 (2020).

44. Croese, S. Sustainable Cities Survey 2018, Luanda. DataFirst https://doi.org/ 10.25828/ed1q-2q89 (2020).

45. Croese, S. Sustainable Cities Survey 2019, Maputo. DataFirst https://doi.org/ 10.25828/acd7-7q30 (2020).

46. UNDP. Gender as an accelerator for achieving the Sustainable Development Goals (UNDP, 2019)

47. Martin, R. V. et al. No one knows which city has the highest concentration of fine particulate matter. Atmos. Environ. 3, 100040 (2019).

48. West, S. E. et al. Particulate matter pollution in an informal settlement in Nairobi: Using citizen science to make the invisible visible. Appl. Geogr. 114 102133 (2020)

49. Ulbrich, P., Porto de Albuquerque, J. \& Coaffee, J. The impact of urban inequalities on monitoring progress towards the sustainable development goals: methodological considerations. ISPRS Int. J. Geo.-Inf. 8, 6 (2019).

50. Patel, A., Joseph, G., Shrestha, A. \& Foint, Y. Measuring deprivations in the slums of Bangladesh: implications for achieving sustainable development goals. Hous. Soc. 46, 81-109 (2019).

51. Flinders, M., Wood, M. \& Cunningham, M. The politics of co-production: risks, limits and pollution. Evid. Policy 12, 261-279 (2016).

52. Shulla, K., Filho, W. L., Sommer, J. H. \& Salvia, A. L. Channels of collaboration for citizen science and the sustainable development goals. J. Clean. Prod. 264 121735 (2020).

53. Trott, C. D., Weinberg, A. E. \& Sample McMeeking, L. B. Prefiguring sustainability through participatory action research experiences for undergraduates: reflections and recommendations for student development. Sustainability 10 3332 (2018)

54. Patel, S., Baptist, C. \& d'Cruz, C. Knowledge is power-informal communities assert their right to the city through SDI and community-led enumerations. Environ. Urban. 24, 13-26 (2012).

55. Chakraborty, A., Wilson, B., Sarraf, S. \& Jana, A. Open data for informal settlements: toward a user's guide for urban managers and planners. J. Urban Manag. 4, 74-91 (2015).

56. Government of Mozambique. Voluntary National Review of Agenda 2030 for Sustainable Development Mozambique https://sustainabledevelopment.un.org/content/ documents/26314VNR_2020_Mozambique_Report.pdf (2020). 


\section{ACKNOWLEDGEMENTS}

The authors thank all members of the local research teams in Luanda and Maputo and all of those who participated in and contributed to the various meetings, workshops and trainings throughout this project. A special thanks to João Domingos at Development Workshop Angola, Danilo Alane at CAP, Pedro Laice at ANAMM and Isabel Emerson in Maputo. Sarah Meny-Gibert insightfully assisted with data cross-tabulation and analysis. The research was supported by the LIRA 2030 Africa Programme, implemented by the International Science Council (ISC) in partnership with the Network of African Science Academies (NASAC) with support from the Swedish International Development Cooperation Agency (Sida). Material support is acknowledged from the Social Sciences and Humanities Research Council (SSHRC) and the International Development Research Centre (IDRC) under the International Partnerships for Sustainable Societies (IPaSS) Programme for the use of the tablets that were provided under this collaboration in Maputo. The corresponding author also acknowledges support from the PEAK Urban programme, funded by the UK Research and Innovation Global Challenges Research Fund, grant reference ES/P011055/1. The views expressed herein do not necessarily represent those of the funders.

\section{AUTHOR CONTRIBUTIONS}

S.C., M.D. and I.R. contributed to the conception and design of the study and the acquisition and interpretation of data. S.C. wrote the article and M.D. and I.R reviewed, commented and gave final approval of the version to be published.

\section{COMPETING INTERESTS}

The authors declare no competing interests.

\section{ADDITIONAL INFORMATION}

Supplementary information is available for this paper at https://doi.org/10.1038/ s42949-020-00006-6.

Correspondence and requests for materials should be addressed to S.C.

Reprints and permission information is available at http://www.nature.com/ reprints

Publisher's note Springer Nature remains neutral with regard to jurisdictional claims in published maps and institutional affiliations.

cc) (1)

Open Access This article is licensed under a Creative Commons Attribution 4.0 International License, which permits use, sharing, adaptation, distribution and reproduction in any medium or format, as long as you give appropriate credit to the original author(s) and the source, provide a link to the Creative Commons license, and indicate if changes were made. The images or other third party material in this article are included in the article's Creative Commons license, unless indicated otherwise in a credit line to the material. If material is not included in the article's Creative Commons license and your intended use is not permitted by statutory regulation or exceeds the permitted use, you will need to obtain permission directly from the copyright holder. To view a copy of this license, visit http://creativecommons. org/licenses/by/4.0/.

(c) The Author(s) 2021 